\title{
Distributions and photosynthesis of phototrophs in sea-surface films
}

\author{
John J. Cullen ${ }^{1}$, Hugh L. MacIntyre ${ }^{1}$, David J. Carlson ${ }^{2}$ \\ ${ }^{1}$ Bigelow Laboratory for Ocean Sciences, West Boothbay Harbor, Maine 04575, USA \\ ${ }^{2}$ College of Oceanography, Oregon State University, Corvallis, Oregon 97331, USA
}

\begin{abstract}
An automatic sampler was used to collect water from the sea-surface microlayer and from $10 \mathrm{~cm}$ below the surface during repeated transects in the Damariscotta estuary, Maine, USA. The fluorescence of chlorophyll $a$ : ultraviolet absorbance, temperature and conductivity were measured continuously. Discrete samples were taken for measurements of chlorophyll concentration, in vivo fluorescence, and photosynthesis vs irradiance (P-I). Patterns observed during the transects were in substantial agreement with a previous study of surface films in the Damariscotta estuary, but the spatial resolution was vastly better. Dissolved organic matter, as indicated by ultraviolet absorbance, and photosynthetic cells (in vivo fluorescence) showed similar patterns of enrichment in slicks. Chlorophyll concentrations were highest in slicks, with enhancements in some of 5 times or more over subsurface water. In clean regions, however, chlorophyll in the surface layer was often slightly depleted as compared to subsurface water. The photoautotrophs in surface films were photosynthetically competent and physiologically similar to those from $10 \mathrm{~cm}$ below the surface, with P-I curves quite typical for healthy phytoplankton. It is possible that photosynthesis in sea surface films was mildly inhibited by solar radiation, but severe stress from exposure to bright light was evident neither in fresh samples nor in those held in bottles at the surface for several hours.
\end{abstract}

\section{INTRODUCTION}

The sea-surface is the most observable feature of the ocean and all information obtained from airborne sensors comes from or through the sea-surface microlayer (SSM). The SSM is an interface, and as such it is physically distinct from the underlying water. It is ecologically distinct as well. Dissolved substances, particulate matter and a wide variety of organisms can concentrate in the SSM, making some sea-surface films highly productive microhabitats (Hardy 1982). The airwater interface can also be a stressful, extreme environment: incident solar radiation is harmful or even lethal to many organisms (Hardy 1982, Neale 1987).

There is a strong base of information on the distributions and activities of microorganisms in sea surface films (Carlson 1982c, Hardy 1982, Williams et al. 1986). Numerous studies have described a microbial flora in the SSM that is distinct from that in the underlying water (review: Hardy 1982). It has also been observed that photoautotrophic biomass, as indicated by chlorophyll $a$, is concentrated in sea-surface films, especially in visible slicks (Williams et al. 1986 and references therein). Where the sea surface is not modified by slicks, chlorophyll may be depleted in the SSM (Carison 1982c).

Differences in phototrophic biomass and taxonomic composition between the SSM and the water column can arise from differential adherence of microorganisms to surface films, vertical migration of motile phytoplankton, buoyancy, and different rates of net growth in the SSM as compared to the underlying water (cf. Hardy 1982). Because the dynamics of sea-surface films are poorly understood, the relative importance of each of these processes is not easily determined. It can be inferred nonetheless that the unique environment of the SSM influences the physiological and ecological characteristics of the biota. Also, it is likely that biological activities in the SSM modify the physical and chemical characteristics of the surface film. It is difficult to assess these biological and chemical processes, however, because the residence times of particles in the sea-surface microlayer are not known.

Studies of the SSM have been hampered by the shortcomings of discrete sampling: limited temporal 
and spatial resolution, small volume available for analyses, and restrictions on the variety of environments that can be sampled. Significant advances can be made by using new techniques for continuous sampling and for experimentation on small samples. The appropriate technology has been developed (Lewis \& Smith 1983, Carlson et al. 1988). We describe here results of continuous sampling of the SSM and underlying water and discuss experiments on samples from these strata. The emphasis is on photosynthetic microorganisms. A clearer picture of the distributions and activities of phototrophs in the SSM is developed.

\section{MATERIALS AND METHODS}

Sampling was performed in the Damariscotta estuary, Maine, USA, during May and September 1987. The hydrography and morphology of the estuary have been described by McAlice (1977) and studies on seasurface films in the area have been published by Carlson (1982a, b, c). An automated device, designated the SCUMS (self contained underway microlayer sampler, Carlson et al. 1988) was used for continuous sampling of the SSM and water from $10 \mathrm{~cm}$ below the surface. Sensors mounted on the SCUMS measured conductivity and temperature at $10 \mathrm{~cm}$ below the surface. Flow rate was about $100 \mathrm{ml} \mathrm{min}{ }^{-1}$. Given the surface area and rate of rotation of the cylinder, this flow is consistent with a layer of about $50 \mu \mathrm{m}$ adhering to a glass plate (Carlson 1982a). Each stream was directed in series through a UV detector $(280 \mathrm{~nm})$ and a flowthrough fluorometer (Turner Designs 10-005R with micro cuvette). The delay time in the system was less than $60 \mathrm{~s}$. Samples were collected from the stream for further analysis and experimentation. For comparisons of sampling techniques, discrete samples of surface films in visible slicks were taken with a Nitex screen sampler (Carlucci et al. 1985) or a stainless steel screen. sampler. Corresponding samples from $10 \mathrm{~cm}$ below the surface were obtained by submerging clean bottles.

Concentrations of chlorophyll $a$, corrected for pheopigment, were determined fluorometrically on samples collected on Whatman GF/F filters and extracted in 10 $\mathrm{ml} 90 \%$ acetone in the dark for at least $24 \mathrm{~h}$ at $0^{\circ} \mathrm{C}$. To see if some of the pigment was resistant to extraction, a parallel series of samples was extracted in a $4: 6$ mix of DMSO (dimethylsulfoxide) and 90\% acetone (Welschmeyer \& Cullen unpubl.; cf. Shoaf \& Lium 1976). No significant differences were found. A Turner Designs 10-005R fluorometer was used for discrete measurements of the fluorescence of chlorophyll a in vivo Fluorescence was measured after 15 min adaptation in the dark and then again after exposure to $3 \times 10^{-6} \mathrm{M}$ DCMU (3-[3,4-dichlorophenyl]-1,1-dimethylurea) in ethanol (Vincent et al. 1984). The initial fluorescence reading $(\mathrm{F})$ was made after $15 \mathrm{~s}$ in the fluorometer. Fluorescence in the presence of DCMU $\left(F_{d}\right)$ was recorded after in the fluorometer.

The method of Lewis \& Smith (1983) was used to make measurements of photosynthesis as a function of irradiance (expressed as photosynthetically active photon flux density, PPFD; $\mu$ mol $\mathrm{m}^{-2} \mathrm{~s}^{-1}$ ). Samples were inoculated with ${ }^{14} \mathrm{C}$-bicarbonate (final activity, ca $3 \mu \mathrm{Ci} \mathrm{ml} \mathrm{m}^{-1}$ ) and aliquots of $1 \mathrm{ml}$ each were dispensed into clean scintillation vials in an incubator with a wide range of PPFD. Light was provided by 4 ENH projection lamps and was measured with a Biospherical Instruments QSL-100 sensor inserted into a scintillation vial. The exact amount of label added was determined by subsampling into $7 \mathrm{ml}$ scintillation fluor (Ecolume, ICN) plus $0.2 \mathrm{ml}$ phenethylamine. Incubations were terminated after 20 or $30 \mathrm{~min}$ by turning off the lights and adding $50 \mu \mathrm{l}$ buffered formalin. Inorganic carbon was expelled by adding acid and agitating the vials in a hood. Total $\mathrm{CO}_{2}$ was assumed to be $2 \mathrm{mM}$. All measurements were corrected for quench and a time-zero control. No correction for isotope discrimination was made.

The photosynthesis vs irradiance (P-I) equation of Platt et al. (1980) was used to model photosynthesis as a function of light:

$$
P_{1}=P_{s} \quad\left(1-e^{-\Omega l / P_{s}}\right) \quad\left(e^{-P L / P P_{s}}\right)
$$

where

$P_{i}\left(g C[g c h l a]^{-1} h^{-1}\right)=$ instantaneous rate of photosynthesis normalized to chlorophyll a at PPFD i; $P_{s}$ (g C [g chl a $]^{-1} \mathrm{~h}^{-1}$ ) = maximum rate of photosynthesis in the absence of photoinhibition: $\alpha\left(\mathrm{gC}[\mathrm{g} \mathrm{chl} \mathrm{a}]^{-1} \mathrm{~h}^{-1}\right.$ [umol $\mathrm{m}^{-2} \mathrm{~s}^{-1} \mathrm{l}^{-1}$ ) = initial slope of the P-I curve; $\beta$ ( $\mathrm{g} \mathrm{C}$ [g chl a $\left.]^{-1} \mathrm{~h}^{-1}\left[\mathrm{\mu mol} \mathrm{m} \mathrm{m}^{-2} \mathrm{~s}^{-1}\right]^{-1}\right)=$ parameter chosen to characterize the degree of photoinhibition.

Photosynthesis is normalized to chlorophyll, but for convenience the superscript B has been omitted. Parameters were fit simultaneously using the multivariate secant method (Ralston \& Jennrich 1978) of the NLIN procedure of SAS (SAS Institute Inc. 1985). For fitting the data, the intercept, $\mathrm{P}_{0},\left(\mathrm{~g} \mathrm{C}[\mathrm{g} \mathrm{chl} \mathrm{a}]^{-1} \mathrm{~h}^{-1}\right.$ ) was included as a parameter and subsequently subtracted from estimates of $P_{i}$ as one would do with a dark bottle value. The parameter $P_{0}$ is not a reliable measure of respiration because of limitations of tracer methodology (Jassby \& Platt 1976, Peterson 1980). Rather, the inclusion of $\mathrm{P}_{0}$ increases the amount of variability explained and improves the distribution of residuals. By subtracting $\mathrm{P}_{0}$ from estimates of $\mathrm{P}_{\mathrm{j}}$ rather than leaving it in, the modelled photosynthesis in the dark is always zero.

The realized maximal rate of photosynthesis, $P_{\max }$ 
( $\mathrm{g} \mathrm{C}[\mathrm{g} \mathrm{chl} \mathrm{a}]^{-1} \mathrm{~h}^{-1}$ ), was calculated using the following equation (Platt et al. 1980):

$$
P_{\max }=P_{s}\left(\frac{\alpha}{\alpha+\beta}\right) \cdot\left(\frac{\beta}{\alpha+\beta}\right)^{\beta / \alpha}
$$

The error associated with $P_{\max }$ was determined (Davis \& Cullen unpubl.) according to the principles described by Zimmerman et al. (1987).

\section{RESULTS}

Continuous records of UV absorbance, in vivo fluorescence, temperature and salinity graphically describe features of the SSM and underlying water. Exemplary data from part of one transect are presented in Fig. 1. The water surface during the transect was
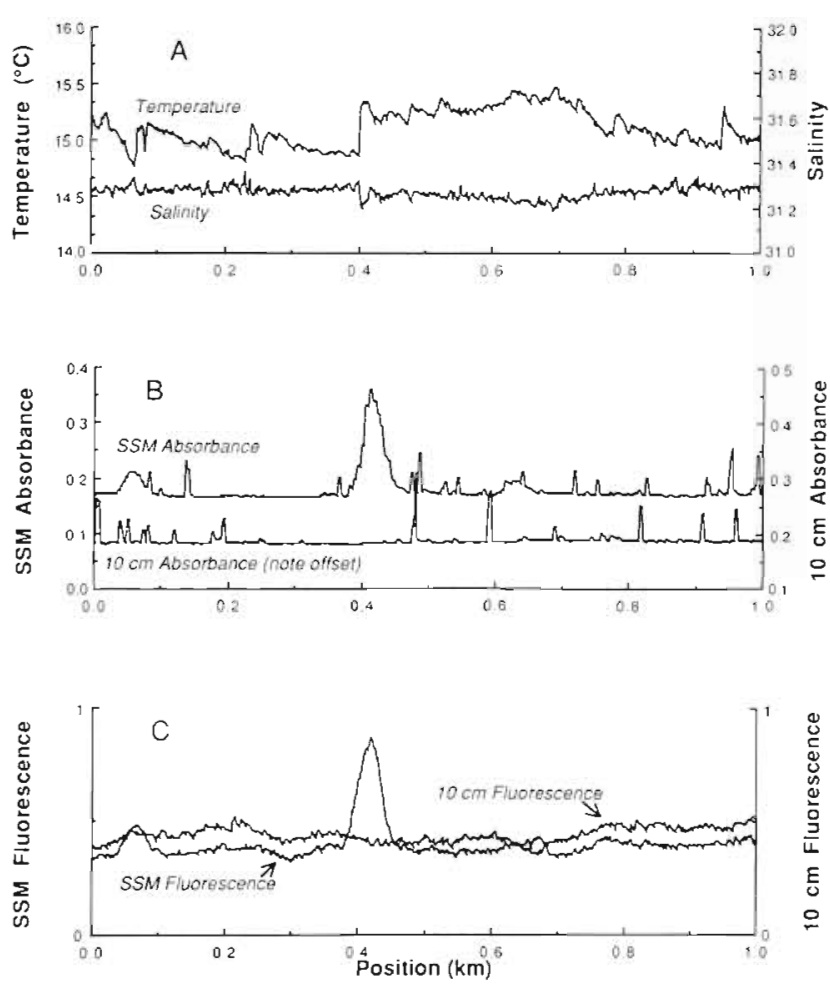

Fig. 1. Records from $1 \mathrm{~km}$ of a transect in the Damariscotta estuary, 14 September 1987, ca 13:30 h. Samples are from the SSM and $10 \mathrm{~cm}$ below the surface. (A) Temperature and salinity (\%o) at $10 \mathrm{~cm}$ below the surface; (B) ultraviolet absorbance (note offset of $10 \mathrm{~cm}$ record); (C) fluorescence of chlorophyll a in vivo

quite clean, with only a few visible slicked streaks. Surface waves were about $15 \mathrm{~cm}$, most with breaking crests. It is likely that generalizations reported here will be modified as larger temporal and spatial scales are considered.

Ultraviolet absorbance is primarily attributable to dissolved organic compounds, some of which are con- centrated in surface slicks (Carlson 1982b, c). During transects in the Damariscotta estuary, patches of high UV absorbance (Fig. 1B) could be visually identified as slicks. These features corresponded to discontinuities in the records of temperature and salinity at $10 \mathrm{~cm}$ (Fig. 1A). Ultraviolet absorbance in the surface layer varied independently of that in the subsurface water. Slight depletion of UV-absorbing compounds in the surface layer was observed in clean areas. The generality of surface depletion of UV absorbance has not yet been determined.

The fluorescence of chlorophyll a was maximal in the slicks, corresponding well to UV absorbance. Like UV absorbance, fluorescence in the SSM was much more variable than and not closely correlated to fluorescence in the underlying water (Fig. 1C). Measurements of chlorophyll on discrete samples verify that the high fluorescence in slicks represents particulate chlorophyll a (Fig. 2). Enrichment ratios (SSM/subsurface) were less than 1.0 over wide expanses of clear water but much higher than 1 in patches.

Numerous spikes were observed in the absorbance record but not in fluorescence (Fig. 1B, C). These spikes are attributable to small bubbles which were observed visually during sampling. The bubbles were lined up in rows at the surface and may have also been transported to the underlying water. The cuvette in the fluorometer was much larger than that in the UV detector, so small bubbles had little effect. The relative smoothness of the fluorescence record is thus not surprising.

Experiments were conducted to see if the SCUMS sampler or the detectors damaged or poisoned the phototrophs from the SSM. The P-I relationship and fluorescence of chlorophyll a in vivo were measured to assess the physiological status of the autotrophs (Cullen et al. 1986). Other samplers were used as controls, with the recognition that some differences are to be expected because of patchiness and differences in film thicknesses sampled (Carlson 1982a). In each of 3 direct comparisons (Table 1; see also Carlson et al. 1988), the SCUMS sample compared favorably to the control, although in one comparison (14 Sep), $\mathrm{P}_{\max }$ from the SCUMS sample was about $23 \%$ lower than that from the Nitex screen sample. Measurements of DCMU-enhanced fluorescence soon after sampling and after incubations of several hours showed no progressive decline, indicating little toxicity or any other progressive inhibition in samples from the SCUMS or the stainless steel screen sampler (data not shown here; see Cullen et al. 1986).

If the surface layer assemblage were stressed by exposure to bright light, it would be expected to have relatively poor photosynthetic performance (i.e. low values of $\alpha$ and $P_{\max }$ : cf. Neale 1987). Photosynthetic 

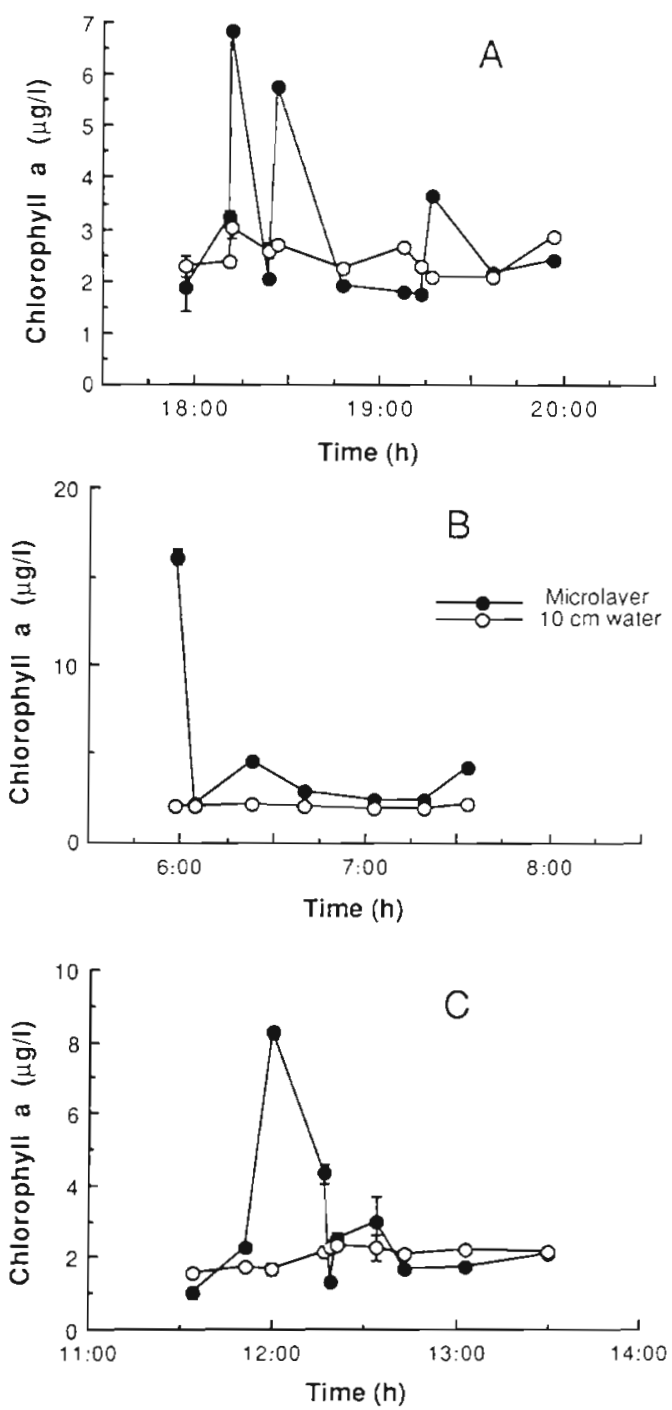

Fig. 2. Measurements of chlorophyll a concentration on samples taken during transects. Each transect was a return trip down the estuary, covering ca $9.5 \mathrm{~km}$. Samples were taken periodically from the SCUMS sampler outflow. Lines connect the means of each pair of determinations: they are not intended to suggest patterns between sampling points. ( $\mathrm{SSM}_{i}$ (O) $10 \mathrm{~cm}$ below the surface. (A) 9 September 1987; (B) 11 September 1987; (C) 14 September 1987

parameters for surface layer samples were generally lower than those for the paired bulk water samples, but not by a large amount (Table 1): the ratio of $\mathrm{P}_{\max }$ for the SSM to $\mathrm{P}_{\max }$ for the bulk water averaged 0.89 (SD = $0.16, n=11$ pairs). Generally, the P-I relationships for samples from the SSM and underlying water were similar to those observed for samples from the water column in temperate latitudes (Harrison \& Platt 1986). There was therefore no obvious indication of severe stresses in the SSM assemblage, nor was there any suggestion that the SSM assemblages were specially adapted as compared to those just below the surface.
Other measurements of photosynthesis by SSM assemblages were reviewed by Williams et al. (1986).

Measurements of in vivo fluorescence reflect some aspects of the physiology of microalgae, particularly responses to bright light (Vincent 1980, Vincent et al. 1984, Neale \& Richerson 1987, Cullen et al. 1988). After exposure to bright light, microalgae exhibit a decline of fluorescence yield with a characteristic time scale of about 10 to $30 \mathrm{~min}$ (Vincent 1980, Cullen \& Lewis 1988). We measured fluorescence yield (flow-through in vivo fluorescence/extracted chlorophyll a) for a number of paired samples during each transect (Fig. 3). For most of the transects, no consistent reduction of fluorescence was observed in surface layer samples,
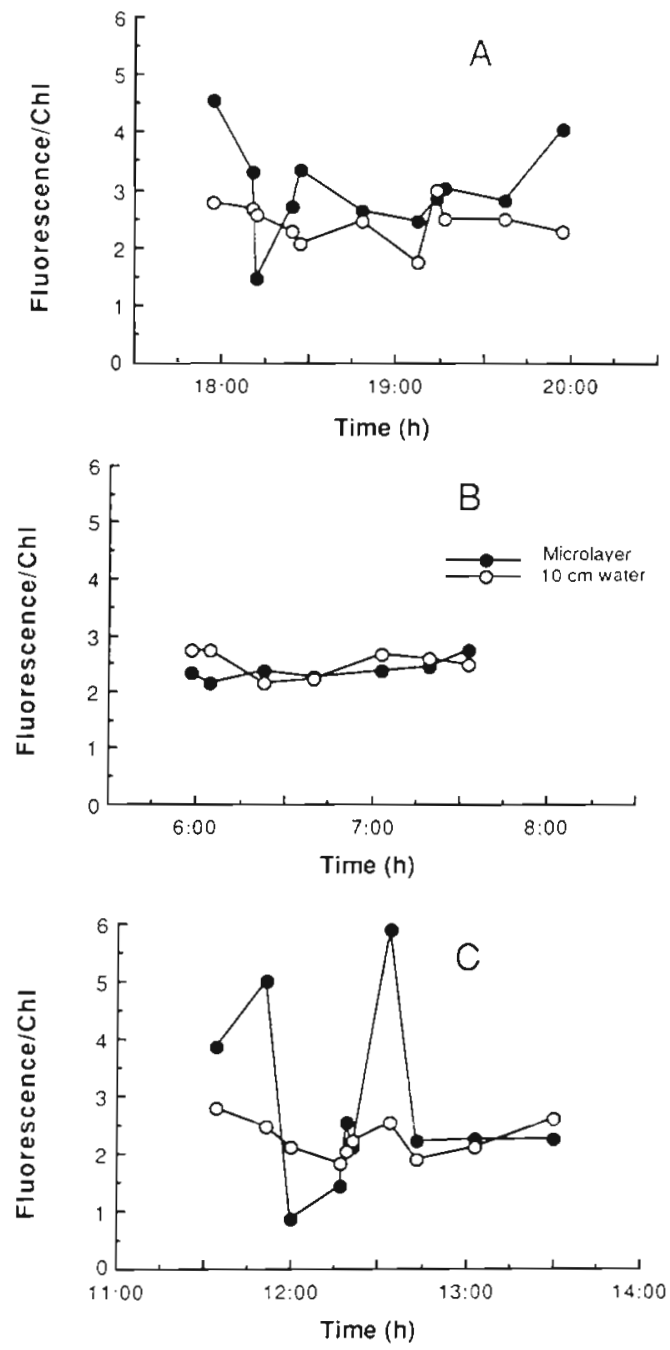

Fig. 3. Flunrescence yield (in vivo fluorescence/extracted chlorophyll a) of samples taken during transects. Results are expressed in relative units, comparable between transects. Same transects as in Fig. 2: (A) 9 September 1987; (B) 11 September 1987; (C) 14 September 1987. (•) SSM; 10) $10 \mathrm{~cm}$ below the surface. Some of the variability in SSM determmations is due to the difficulty of sampling transient peaks of fluorescence during transects 
Table 1 Comparison of SSM and subsurface assemblages from the Damariscotta estuary, Maine, USA. Chlorophyll a concentration and photosynthesis vs irradiance for paired samples. Numbers in parentheses are standard errors of the estimate. Units: chlorophyll $a, \mu \mathrm{gl}^{-1} ; \mathrm{P}_{\max }, \mathrm{gC}(\mathrm{g} \mathrm{chl} \mathrm{a})^{-1} \mathrm{~h}^{-1} ; \alpha$ and $\beta, \mathrm{g} \mathrm{C}(\mathrm{g} \mathrm{chl} a)^{-1} \mathrm{~h}^{-1}\left(\mu \mathrm{mol} \mathrm{m}{ }^{-2} \mathrm{~s}^{-1}\right)^{-1}$ A.bbreviations for SSM samplers: Ni $=$ Nitex screen sampler; $\mathrm{St}=$ Stainless Steel sampler; $\mathrm{SC}=$ SCUMS. The ratio of SSM : $10 \mathrm{~cm}$ for Beta is not presented as it is not meaningful

\begin{tabular}{|c|c|c|c|c|c|c|c|c|c|c|c|c|c|}
\hline \multirow{2}{*}{\multicolumn{2}{|c|}{ Date/time }} & \multirow[t]{2}{*}{ Sampler } & \multicolumn{3}{|c|}{ Chlorophyll } & \multicolumn{3}{|c|}{$P_{\max }$} & \multicolumn{3}{|c|}{$\alpha$} & \multicolumn{2}{|c|}{$\beta$} \\
\hline & & & SSM & $10 \mathrm{~cm}$ & Ratio & SSM & $10 \mathrm{~cm}$ & Ratio & SSM & $10 \mathrm{~cm}$ & Ratio & SSM & $10 \mathrm{~cm}$ \\
\hline 9 May & $11: 45 \mathrm{~h}$ & $\mathrm{Ni}$ & $\begin{array}{c}1.51 \\
(0.10)\end{array}$ & $\begin{array}{l}1.36 \\
(0.07)\end{array}$ & 1.11 & $\begin{array}{c}3.55 \\
(0.65)\end{array}$ & $\begin{array}{c}3.37 \\
(0.69)\end{array}$ & 1.06 & $\begin{array}{c}0.042 \\
(0.020)\end{array}$ & $\begin{array}{c}0.041 \\
(0.032)\end{array}$ & 1.02 & $\begin{array}{c}0.0000 \\
(0.00033)\end{array}$ & $\begin{array}{l}0.0000 \\
(0.0)\end{array}$ \\
\hline 9 May & $12: 40 \mathrm{~h}$ & SC & $\begin{array}{c}1.38 \\
(0.05)\end{array}$ & $\begin{array}{c}0.90 \\
(0.02)\end{array}$ & 1.54 & $\begin{array}{c}3.60 \\
(0.31)\end{array}$ & $\begin{array}{c}2.97 \\
(0.74)\end{array}$ & 1.21 & $\begin{array}{c}0.022 \\
(0.005)\end{array}$ & $\begin{array}{c}0.016 \\
(0.010)\end{array}$ & 1.39 & $\begin{array}{c}0.0005 \\
(0.00025)\end{array}$ & $\begin{array}{c}0.0007 \\
(0.00092)\end{array}$ \\
\hline 11 May & $11: 45 \mathrm{~h}$ & St & $\begin{array}{c}3.45 \\
(0.17)\end{array}$ & $\begin{array}{c}1.27 \\
(0.03)\end{array}$ & 2.72 & $\begin{array}{l}2.28 \\
(0.17)\end{array}$ & $\begin{array}{l}3.40 \\
(0.31)\end{array}$ & 0.67 & $\begin{array}{c}0.016 \\
(0.004)\end{array}$ & $\begin{array}{c}0.011 \\
(0.003)\end{array}$ & 1.43 & $\begin{array}{l}0.0003 \\
(0.00017)\end{array}$ & $\begin{array}{l}0.0007 \\
(0.00065)\end{array}$ \\
\hline 11 May & $12: 40 \mathrm{~h}$ & SC & $\begin{array}{c}1.12 \\
(0.03)\end{array}$ & $\begin{array}{c}1.67 \\
(0.04)\end{array}$ & 0.68 & $\begin{array}{c}3.11 \\
(0.29)\end{array}$ & $\begin{array}{c}3.74 \\
(0.49)\end{array}$ & 0.83 & $\begin{array}{c}0.021 \\
(0.006)\end{array}$ & $\begin{array}{c}0.019 \\
(0.009)\end{array}$ & 1.11 & $\begin{array}{c}0.0001 \\
(0.00023)\end{array}$ & $\begin{array}{l}0.0000 \\
(0.0)\end{array}$ \\
\hline $14 \mathrm{Sep}$ & $09: 35 \mathrm{~h}$ & $\mathrm{SC}$ & $\begin{array}{c}2.44 \\
(0.16)\end{array}$ & $\begin{array}{c}2.09 \\
(0.08)\end{array}$ & 1.17 & $\begin{array}{c}3.94 \\
(0.18)\end{array}$ & $\begin{array}{c}4.37 \\
(0.24)\end{array}$ & 0.90 & $\begin{array}{c}0.028 \\
(0.004)\end{array}$ & $\begin{array}{c}0.024 \\
(0.004)\end{array}$ & 1.14 & $\begin{array}{l}0.0000 \\
(0.00013)\end{array}$ & $\begin{array}{c}0.0003 \\
(0.00026)\end{array}$ \\
\hline $14 \mathrm{Sep}$ & $10: 10 \mathrm{~h}$ & Ni & $\begin{array}{c}2.53 \\
(0.05)\end{array}$ & $\begin{array}{c}2.12 \\
(0.22)\end{array}$ & 1.19 & $\begin{array}{c}5.11 \\
(0.23)\end{array}$ & $\begin{array}{c}5.53 \\
(0.53)\end{array}$ & 0.93 & $\begin{array}{c}0.033 \\
(0.005)\end{array}$ & $\begin{array}{c}0.037 \\
(0.013)\end{array}$ & 0.90 & $\begin{array}{c}0.0002 \\
(0.00024)\end{array}$ & $\begin{array}{l}0.0000 \\
(0.0)\end{array}$ \\
\hline $15 \mathrm{Sep}$ & $08: 10 \mathrm{~h}$ & $\mathrm{SC}$ & $\begin{array}{l}27.80 \\
(1.24)\end{array}$ & $\begin{array}{c}2.35 \\
(0.03)\end{array}$ & 11.85 & $\begin{array}{c}3.39 \\
(0.09)\end{array}$ & $\begin{array}{l}4.84 \\
(0.20)\end{array}$ & 0.70 & $\begin{array}{c}0.031 \\
(0.002)\end{array}$ & $\begin{array}{c}0.048 \\
(0.006)\end{array}$ & 0.64 & $\begin{array}{c}0.0002 \\
(0.00007)\end{array}$ & $\begin{array}{c}0.0003 \\
(0.00016)\end{array}$ \\
\hline $15 \mathrm{Sep}$ & $11: 30 \mathrm{~h}$ & $\mathrm{SC}$ & $\begin{array}{c}1.51 \\
(0.26)\end{array}$ & $\begin{array}{c}2.09 \\
(0.02)\end{array}$ & 0.73 & $\begin{array}{c}3.72 \\
(1.00)\end{array}$ & $\begin{array}{c}4.24 \\
(0.67)\end{array}$ & 0.88 & $\begin{array}{c}0.022 \\
(0.021)\end{array}$ & $\begin{array}{c}0.033 \\
(0.012)\end{array}$ & 0.69 & $\begin{array}{c}0.0000 \\
(0.0)\end{array}$ & $\begin{array}{c}0.0000 \\
(0.00058)\end{array}$ \\
\hline $15 \mathrm{Sep}$ & $13: 40 \mathrm{~h}$ & SC & $\begin{array}{l}3.28 \\
(0.09)\end{array}$ & $\begin{array}{c}2.39 \\
(0.06)\end{array}$ & 1.37 & $\begin{array}{c}4.13 \\
(0.29)\end{array}$ & $\begin{array}{c}5.13 \\
(0.47)\end{array}$ & 0.80 & $\begin{array}{c}0.026 \\
(0.006)\end{array}$ & $\begin{array}{c}0.046 \\
(0.010)\end{array}$ & 0.56 & $\begin{array}{c}0.0002 \\
(0.00032)\end{array}$ & $\begin{array}{c}0.0000 \\
(0.00038)\end{array}$ \\
\hline $18 \mathrm{Sep}$ & $10: 45 \mathrm{~h}$ & SC & $\begin{array}{l}4.34 \\
(0.05)\end{array}$ & $\begin{array}{c}4.90 \\
(0.10)\end{array}$ & 0.89 & $\begin{array}{l}3.70 \\
(0.31)\end{array}$ & $\begin{array}{c}4.87 \\
(0.34)\end{array}$ & 0.76 & $\begin{array}{c}0.014 \\
(0.004)\end{array}$ & $\begin{array}{c}0.036 \\
(0.007)\end{array}$ & 0.40 & $\begin{array}{l}0.0007 \\
(0.00060)\end{array}$ & $\begin{array}{c}0.0002 \\
(0.00022)\end{array}$ \\
\hline $18 \mathrm{Sep}$ & $14: 00 \mathrm{~h}$ & $\mathrm{SC}$ & $\begin{array}{c}3.46 \\
(0.11)\end{array}$ & $\begin{array}{l}4.32 \\
(0.02)\end{array}$ & 0.80 & $\begin{array}{c}4.92 \\
(0.33)\end{array}$ & $\begin{array}{c}4.88 \\
(0.27)\end{array}$ & 1.01 & $\begin{array}{c}0.040 \\
(0.008)\end{array}$ & $\begin{array}{c}0.035 \\
(0.005)\end{array}$ & 1.13 & $\begin{array}{c}0.0001 \\
(0.00018)\end{array}$ & $\begin{array}{c}0.0005 \\
(0.00020)\end{array}$ \\
\hline & & & 4.80 & 2.31 & 2. & 3.77 & 4. & 0. & & 0.0 & & & \\
\hline Stan & adard de & viation & 7.70 & 1.24 & 3.25 & 0.79 & 0.83 & 0.16 & 0.009 & 0.012 & 0.34 & 0.00022 & 0.00020 \\
\hline
\end{tabular}

although it was difficult to compare chlorophyll with fluorescence for samples from slicks, because slicks appeared as rapid transients during sampling.

Photosynthetic performance and fluorescence yield should reflect photoinhibition by surface PPFD and recovery at reduced PPFD. Simply, if the assemblage in the SSM is not fully adapted to sea-surface irradiance (i.e. it is sensitive to solar radiation unattenuated by seawater), photosynthetic processes will be inhibited during a static incubation at the sea surface whereas if the assemblage is already inhibited in situ, it will recover during an incubation in reduced light.

To explore the possibility that phototrophs in the SSM are photoinhibited in situ, we performed manipulative experiments. Samples were obtained from the SSM and $10 \mathrm{~cm}$ below the surface, incubated at the surface or under reduced light for several hours, and analysed for P-I, chlorophyll, and fluorescence. Results from one experiment suggest that the bright light at the sea surface was harmful neither to the SSM assemblage nor to the phytoplankton from $10 \mathrm{~cm}$ below the surface (Figs. 4 and 5). Four samples were examined: 'Fresh 1' was sampled by SCUMS at 10:43 h on 18 Sep
1987. Part of the sample was analysed and the remainder was placed in 2 polycarbonate bottles. One ('High Light') was floated at the surface under bright sunlight (about $2200 \mathrm{~mol} \mathrm{~m}^{-2} \mathrm{~s}^{-1}$ ) for $3.5 \mathrm{~h}$, then analysed. The other ('Low Light') was screened ( $8 \%$ transmission plastic film) and incubated just below the surface for $4 \mathrm{~h}$ until analysis. If the Fresh 1 SSM sample had been photoinhibited in situ, it would be expected to recover during the low light incubation. No such recovery was observed (Figs. 4 and 5). The assemblage did respond to manipulation, however: $\beta$, the photoinhibition parameter, declined to 0 during the incubation in bright light (Cullen \& Lewis 1988).

It was hoped that the experimental results could be used to infer the residence time of algal assemblages in the SSM. A sample ('Fresh 2') was taken by SCUMS at 14:00 h. Physiological differentiation in a natural light gradient can be interpreted in terms of vertical exchange between the SSM and underlying water (Lewis et al. 1984, Cullen \& Lewis 1988). Ideally, the SSM and bulk samples from Fresh 2 would show physiological differentiation countered by natural vertical exchange whereas the High Light and Low Light 

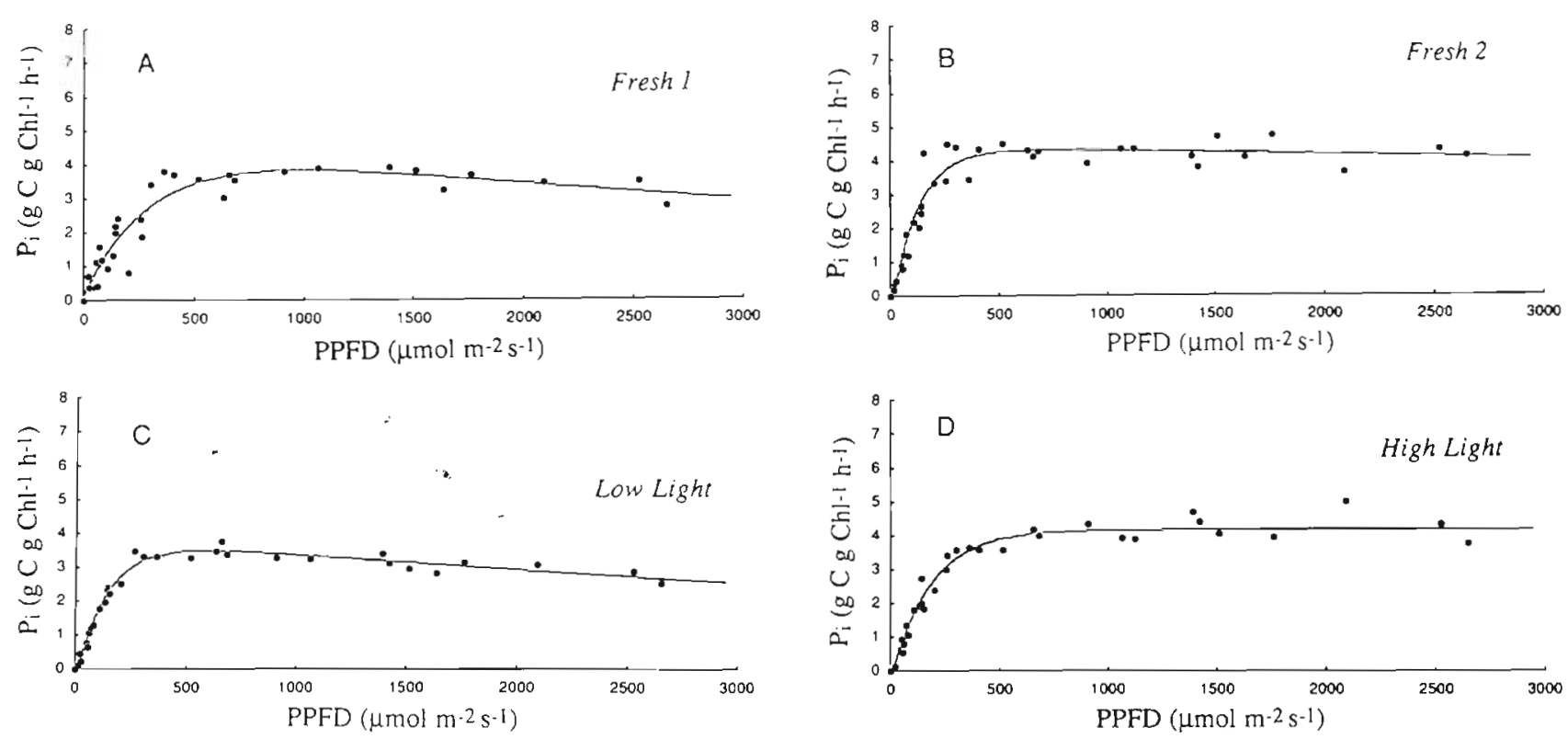

Fig. 4. Photosynthesis vs irradiance: results from manipulative experiment, 14 September 1987. (A) Sample 'Fresh 1 ' was obtained from the SCUMS at 10:43 h and P vs I was measured at 11:03 h. (B) Sample 'Fresh 2 ' was obtained from the SCUMS at 14:02 h and P vs I was measured at 14:17 h. (C) 'Low Light' was a subsample of 'Fresh 1 ' incubated at $8 \%$ surface PPFD until 14:43 h. (D) 'High Light' was another subsample incubated at the surface and harvested at 15:23 h
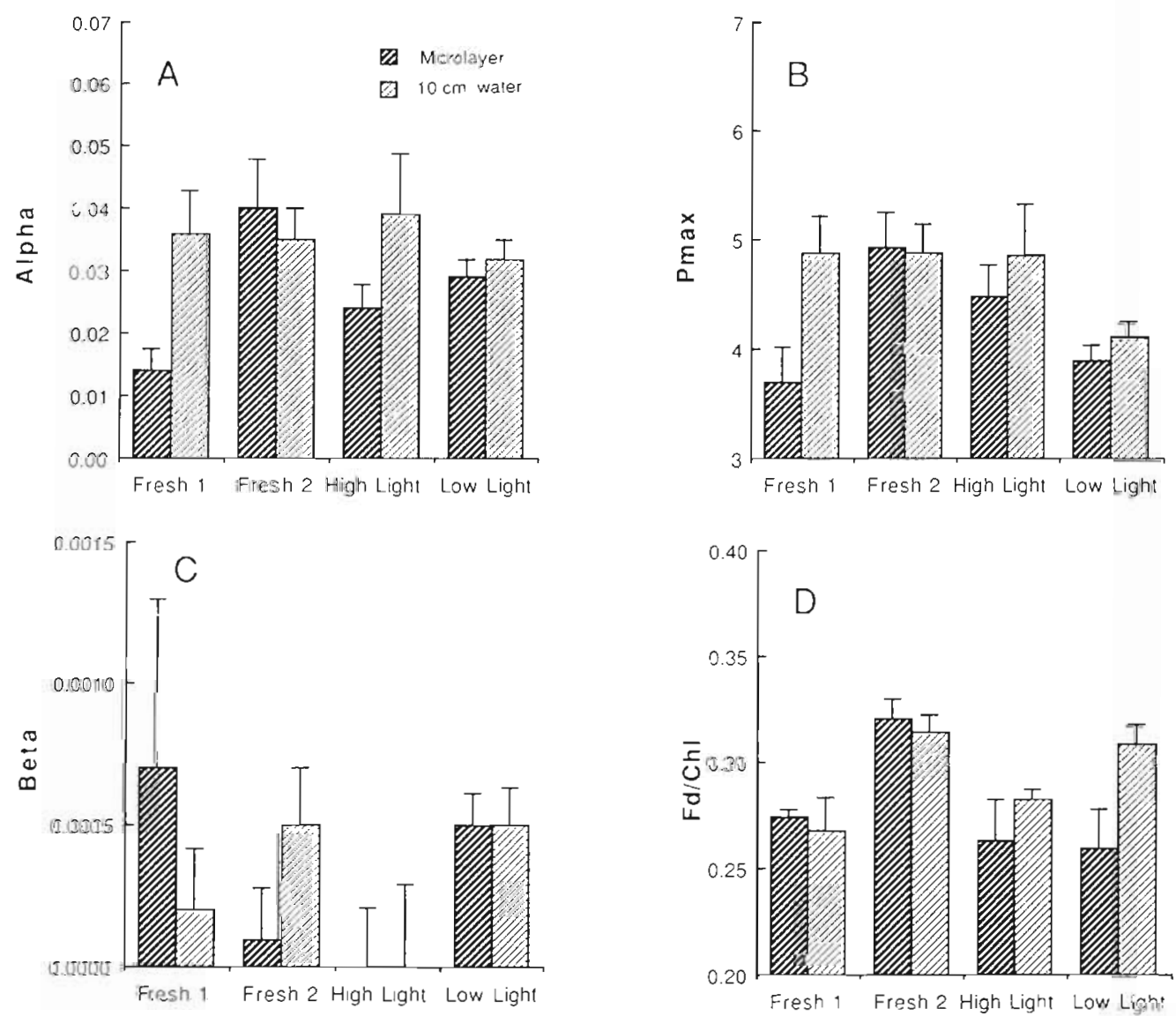

Fig. 5. Results from manipulative experiment, 14 September 1987. Parameters of photosynthesis-irradiance curves (P $\left.P_{\max } \alpha, \beta\right)$ and fluorescence yields $\left(\mathrm{F}_{\mathrm{d}} \mathrm{chl}^{-1}\right)$ for paired samples originally taken from the SSM and $10 \mathrm{~cm}$. Same designations as Fig. 4 . Error bars are standard errors 
samples would show the maximal physiological differentiation associated with constant exposure to high and low PPFD. The incubated samples did show physiological differences that were consistent with adaptation to high and low light $\left(\mathrm{P}_{\max }\right.$ positively correlated with PPFD, $\beta$ goes to zero in high light; Cullen \& Lewis 1988), but differences were small and results for $\alpha$ were variable (Fig. 5). The SSM and bulk samples from Fresh 2 were less differentiated than the incubated samples, but we cannot say with confidence that vertical exchange was responsible.

Somewhat different results for the High Light incubations might have been obtained if quartz bottles (transparent to environmental ultraviolet radiation) had been used rather than polycarbonate bottles (opaque to UV-B radiation). Subsequently, we have made the appropriate comparisons (Cullen et al. unpubl.). Results show that the ultraviolet radiation screened by polycarbonate does affect surface layer phototrophs, but the effect of polycarbonate containers has little bearing on the interpretations presented here.

\section{DISCUSSION}

The continuous transects of UV absorbance, in vivo fluorescence, temperature and salinity are remarkably informative. Most important, perhaps, is the finding that UV absorbance and in vivo fluorescence show similar patterns of enrichment in the SSM. The implication is that the mechanisms important to the formation and maintenance of sea-surface slicks act similarly on dissolved organic compounds and microalgal cells. Techniques such as cross-spectral analysis might be useful in attempts to interpret such patterns effectively.

At the present stage of our analysis, we have observed no patterns in the distributional data inconsistent with previous studies in the Damariscotta estuary (Carlson 1982b, c). The temporal and spatial resolution of our transects is orders of magnitude better, however (about 175000 data), and we expect to develop new insights as analysis proceeds.

The physiological characteristics of phototrophs near the sea surface were examined in a number of ways during our study, Results were fairly consistent, indicating only mild stress associated with exposure to bright light at the sea surface, probably because both surface and near-surface assemblages were well adapted to bright light. The apparent inhibition of photosynthesis at the SSM was somewhat less than that reported by Williams et al. (1986) for samples from waters off the western coast of Baja California. There were no consistent indications in our data that the photoautotrophs in the SSM were physiologically distinct from the phytoplankton. Clearly, the question should be examined in other ways such as floristic analysis and determination of pigments by HPLC.

Because the assemblages of phototrophs were relatively unresponsive to experimental manipulations of irradiance, it was difficult to use experimental results for inferring the residence time of microalgae in the SSM. There were, however, several weak indications that the residence times were fairly short, i.e. much less than a day. First, there were no indications of pronounced physiological differentiation in the SSM; second, results of the manipulative experiment (Figs. 4 and 5) were consistent with vertical exchange with a temporal scale less than several hours; finally, the energetic motions associated with tidal currents in the estuary may have led to rapid turnover of sea-surface films. In other environments, such as the open ocean, where scales and forcing functions are expected to be different than in our study area, much clearer results might be obtained.

\section{CONCLUSIONS}

The study of chlorophyll and photosynthesis in seasurface microlayers is at a stage comparable to that of phytoplankton ecology when continuous measurements of fluorescence were introduced (Lorenzen 1967). At first, previously recognized patterns were observed, but with much greater resolution than could be obtained by discrete sampling. Later, the capacity for continuous measurement was exploited quite effectively: horizontal patterns were described by spectral analysis (Denman \& Platt 1976), and the mechanisms involved in formation and maintenance of vertical patterns were examined (Cullen 1982). It is likely that continuous measurement of features in the SSM will also be quite useful in future studies, especially in work related to remote sensing of the sea.

Acknowledgements: Supported by the Office of Naval Research Marine Microlayer Accelerated Research Initiative. We thank J. Brophy, R. Knowles, A. Binning and M. Wells for assistance in the field. Bigelow Laboratory Contribution \#89012.

\section{LITERATURE CITED}

Carlucci, A. F., Craven, D. B., Henrichs, S. M. (1985). Surfacefilm microheterotrophs: amino acid metabolism and solar radiation effects on their activities. Mar. Biol. 85: 13-22

Carlson, D. J. (1982a). A field evaluation of plate and screen microlayer sampling techniques. Mar. Chem. 11: 198-208

Carlson, D. J. (1982b). Surface microlayer phenolic enrichments indicate sea surface slicks. Nature, Lond. 296: $426-429$

Carlson, D. J. (1982c). Phytoplankton in marine surface microlayers. Can. J. Microbiol. 28: 1226-1234 
Carlson, D. J., Cantey, J. L., Cullen, J. J. (1988). Description of and results from a new surface microlayer sampling device. Deep Sea Res. 35: 1205-1213

Cullen, J. J. (1982). The deep chlorophyll maximum: comparing vertical profiles of chlorophyll a. Can. J. Fish Aquat. Sci. 39: 791-803

Cullen, J. J., Lewis, M. R. (1988). The kinetics of algal photoadaptation in the context of vertical mixing. J. Plankton Res. 10: 1039-1063

Cullen, J. J., Yentsch, C. M., Cucci, T L., Macintyre, H. L. (1988). Autofluorescence and other optical properties as tools in phytoplankton ecology. In: Blizard, M. A. (ed.) Ocean Optics IX, Proc. SPIE (Society of Photo-Optical Instrumentation engineers, Bellingham, Washington) 925 149-156

Cullen, J. J., Zhu, M., Pierson, D. C. (1986). A technique to assess the harmful effects of sampling and containment for determination of primary production. Limnol. Oceanogr. 31: $1364-1373$

Denman, K. L., Platt, T. (1976). The variance spectrum of phytoplankton in a turbulent ocean. J. mar. Res. 34 593-601

Hardy, J. T (1982). The sea surface microlayer: biology, chemistry and anthropogenic enrichment. Prog. Oceanogr. 11: $307-328$

Harrison, W G., Platt, T. (1986). Photosynthesis-irradiance relationships in polar and temperate phytoplankton populations. Polar Biol. 5: 153-164

Jassby, A. D., Platt, T (1976). Mathematical formulation of the relationship between photosynthesis and light for phytoplankton. Limnol. Oceanogr 21: 540-547

Lewis, M. R., Cullen, J. J., Platt, I (1984). Relationships between vertical mixing and photoadaptation of phytoplankton: similarity criteria. Mar Ecol. Prog. Ser. 15: $141-149$

Lewis, M. R., Smith, J. C. (1983). A small volume, short incubation time method for measurement of photosynthesis as a function of incident irradiance. Mar. Ecol. Prog. Ser 13: 99-102

Lorenzen, C. J. (1967). A method for continuous measurement of in vivo chlorophyll concentration. Deep Sea Res. 13: $223-227$

This article was submitted to the editor
McAlice, B. J. (1977). A preliminary oceanographic survey of the Damariscotta River estuary, Lincoln County, Maine. Maine Sea Grant Tech. Rep. 13. $41 \mathrm{pp}$

Neale, P. J. (1987). Algal photoinhibition and photosynthesis in the aquatic environment. In: Kyle. D., Arntzen, C. J., Osmond, B. (eds.) Photoinhibition. Elsevier, Amsterdam, p. 35-65

Neale, P. J., Richerson, P. J. (1987). Photoinhibition and the diurnal variation of phytoplankton photosynthesis - I. Development of a photosynthesis-irradiance model from studies of in situ responses. J. Plankton Res. 9: 16 $\overrightarrow{7}-193$

Peterson, B. J. (1980). Aquatic primary productivity and the ${ }^{14} \mathrm{C}-\mathrm{CO}_{2}$ method: a history of the productivity problem. Ann. Rev. Ecol. Syst. 11: 359-385

Platt, T., Gallegos, C. L., Harrison, W G. (1980). Photoinhibition of photosynthesis in natural assemblages of marine phytoplankton. J. mar. Res. 38: 687-701

Ralston, M. L., Jennrich, R. I. (1978). DUD, a derivative-free algorithm for nonlinear least squares. Technometrics 20 : $7-14$

SAS Institute Inc. (1985). SAS user's guide: statistics version, 5th edn. SAS Institute Inc., Cary, North Carolina

Shoaf, W. T., Lium, B. W. (1976). Improved extraction of chlorophyll $a$ and $b$ from algae using dimethylsulfoxide. Limnol. Oceanogr. 21: 926-928

Vincent, W F. (1980). Mechanisms of rapid photosynthetic adaptation in natural phytoplankton communities. II. Changes in photochemical capacity as measured by DCMUinduced chlorophyll fluorescence. J. Phycol. 16: 568-577

Vincent, W. F., Neale, P. J., Richerson, P. J. (1984). Photoinhibition: algal responses to bright light during diel stratification and mixing in a tropical alpine lake. J. Phycol. 20: 201-211

Williams, P. M., Carlucci, A. F., Henrichs, S. M., Van Vleet, E. S., Horrigan, S. G., Reid, F. M. H., Robertson, K. J. (1986). Chemical and microbiological studies of sea-surface films in the southern Gulf of California and off the west coast of Baja California. Mar Chem. 19: 17-98

Zimmerman, R. C.. SooHoo, J. B., Kremer, J. N., D'Argenio, D. Z. (1987). Evaluation of variance approximation techniques for non-linear photosynthesis-irradiance models. Mar. Biol. 95: 205-215

Manuscript first received: January 16, 1989

Revised version accepted: May 2, 1989 